\title{
Dental Excellence Award 2015
}

\author{
Das amerikanische On- \\ line Dentalmagazin \\ DrBicuspid.com hat \\ den ORTHOPHOS SL \\ von Dentsply Sirona \\ Imaging als bestes neu- \\ es bildgebendes Gerät \\ (Best New Imaging De- \\ vice) mit dem Dental \\ Excellence Award 2015 \\ ausgezeichnet. Das für \\ 2D- und 3D-Aufnah- \\ men geeignete digitale \\ Röntgengerät mit inno-
} vativen Aufnahmetech-

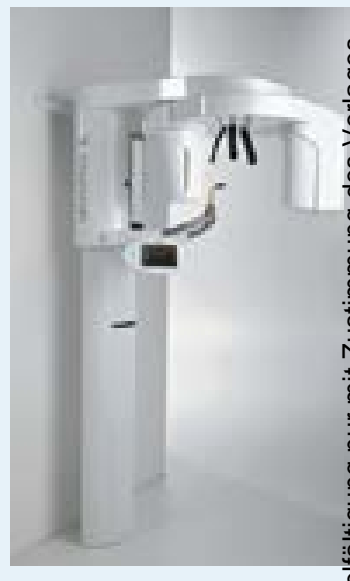
nologien konnte sich im Halbfinale zweier Wahlrunden gegen 5 Mitbewerber durchsetzen. Insgesamt waren für den Dental Excellence Award 65 Produkte aus 9 Kategorien nominiert. Zwei innovative Verfahren sorgen für Aufnahmen mit höchster Zeichenschärfe: Zum einen nutzt der hier erstmalig eingesetzte Direct ConversionSensor die Röntgenstrahlen durch deren direkte Umwandlung in elektrische Signale deutlich besser aus. Dies ermöglicht selbst bei geringster Strahlendosis eine verbesserte Bildqualität. Des Weiteren zeichnet sich das Gerät durch das rekonstruktive Sharp-Layer-Verfahren aus. Dabei ermöglichen mehrere Tausend Einzelprojektionen, die bei 1 Umlauf aufgenommen werden, eine digitale Rekonstruktion, die zu einer verlässlichen Zeichenschärfe führt.

Über Nominierungen und Sieger des begehrten Anwenderpreises entscheiden die Leser von DrBicuspid.com, die Übergabe des Awards erfolgte auf dem Midwinter Meeting der Dental Society Ende Februar in Chicago. Das jährlich stattfindende Dental-Event gilt als der bedeutendste Branchentreff auf dem amerikanischen Kontinent.

Nach einer Pressemitteilung der Dentsply Sirona Imaging, A - Salzburg www.dentsplysirona.com 